\title{
SkillsIdentifier: A Tool to Promote Career Identity and Self-efficacy Among Underrepresented Job Seekers
}

\author{
Tawanna R. Dillahunt \\ University of Michigan \\ tdillahu@umich.edu
}

\author{
Joey Chiao-Yin Hsiao \\ University of Michigan \\ jcyhsiao@umich.edu
}

\begin{abstract}
Today's employment applications enable job seekers to improve their skill sets and build social networks with potential employers and colleagues. However, many of these tools cater to higher-educated and relatively affluent job seekers. Research suggests that underrepresented job seekers face challenges associated with articulating their skill sets and understanding those skills' transferability across jobs and might prefer employment tools to address these types of challenges over others. Because such articulation is vital in today's job market, we designed, developed, and evaluated SkillsIdentifier, a tool to assist job seekers in identifying their current skill set. We evaluated the tool with 20 U.S. job seekers and found that it helped to enhance their career identity and self-efficacy. We contribute the empirical results of our evaluation and design implications for supporting these constructs among underrepresented job seekers.
\end{abstract}

\section{Introduction}

The United States (U.S.) economy can be characterized by rapid technological advancement and organizational shifts [1]. These shifts arguably lead to "boundaryless" careers, or "sequences of job opportunities that go beyond the boundaries of single employment settings" [2, p.307]. Such careers are associated with an individual's career movement. Career movement exists in terms of an individual's perceived capacity to transition within or outside an organization (i.e., psychological mobility), or an individual's career transitions across boundaries (i.e., physical mobility). In an evidence-based review of empirical studies from 1994 to 2018 to understand the relationship between forms of career boundarylessness and career success, Guan et al. found mixed effects depending on various career success indicators [1]. These indicators (i.e., career competencies, structural constraints, and institutional support for boundary-crossing behaviors, voluntary vs. involuntary motives, and individual career resources) are inherently social, economic, and psychological in nature, which muddles the effects of boundaryless careers on career success [1]. The overall trend suggested that positive effects were more apparent among professional samples (e.g., executives, MBAs) than general employee samples (e.g., middle and late career employees). More research is needed, however, to fully interpret Guan et al.'s results; less is known about career success indicators and what works well for less professional workers.

Past work in the domain of human-computer interaction (HCI) has investigated how to design employment tools to support U.S. job seekers who face disadvantages in the job search $[3,4,5]$. This literature is crucial given the recent statistics showing that a significant segment of unemployed people includes racial and ethnic minorities, returning citizens, less-educated people, and those with disabilities [6]. Therefore, we developed SkillsIdentifier, a tool envisioned in prior work to help job seekers "identify and communicate their current skill set" [7, p.5]. We built on Savickas' career construction theory [8] and past digital employment tool to design work for this unemployed population, who we refer to as underrepresented job seekers, to answer the research questions: How does SkillsIdentifier influence underrepresented job seekers on skill articulation? And why or why not?

We employed qualitative methods in a lab study to assess SkillsIdentifier with 20 underrepresented job seekers in a Midwestern U.S. region. The state had an unemployment rate $(\sim 4.1 \%)$, slightly higher than that of the U.S. at the time, but with an unemployment rate much higher among underrepresented job seekers [9]. Our results suggest that the tool enhanced job seekers' career identity, and to an extent, their self-efficacy. This is important because the processes of career planning and reflection contribute to career development and help individuals manage career transitions (e.g., from university to employment or movement across careers) 
[10]. Building on past employment research in HCI and career development theory, we contribute: 1) the implementation and assessment of SkillsIdentifier, an employment tool that enables job seekers to identify the skills that are most appropriate to the job they are currently seeking; 2) empirical results showing that tools that help to uncover previously unidentified job skills could help to enhance career identity and self-efficacy; and 3) design recommendations for further enhancements to SkillsIdentifier or similar tools.

\section{Related Work}

To understand how to design tools to better support the needs of job seekers in a boundaryless-career environment and those who are traditionally underserved by technology, we start our related work by explaining, and then focusing on, barriers to identifying one specific aspect of career competencies-skills and abilities. This is particularly important for underrepresented job seekers. We conclude by discussing educational and employment disparities among our targeted job seekers and the related design, employment, and HCI literature built upon in this work.

\subsection{Career Competencies}

In considering the economy and past $\mathrm{HCI}$ research design among underrepresented job seekers, we chose to focus on career competencies. According to Kuijpers and Scheerens [11, p.305], career competencies are "competencies that are relevant for all employees to develop their own career, regardless of the specific job they have." These competencies have been said to predict career success in a boundaryless career environment [12] and are necessary for people to move within the labor market (i.e., movement capital) [13]. Per DeFillippi and Arthur, the three key competencies are know-why, know-how, and know-whom [2].

Know-why competencies answer the question why as it relates to personal meaning, identification, and career motivation. These competencies shape individuals' abilities to make sense of their evolving work agendas. Approaches to developing these competencies include career development activities, team-building, and specialization [2]. Know-how competencies are reflected in job-related skills and abilities through training or other development activities. Finally, know-whom competencies reflect one's career-related networks that are often built through mentoring programs or via interpersonal relationships [2].

Because these competencies are crucial for boundaryless careers and the context of today's work environment, we framed our work within these competencies. As discussed in the next two subsections, underrepresented job seekers often face barriers to identifying their skills and abilities because of educational and employment disparities. Therefore, tools that support their know-how competencies could be extremely valuable.

\subsection{Barriers and Facilitators to Identifying Skills and Abilities}

Career development theories emphasize the importance of individuals' perceptions of their own abilities [14] and performance self-concept [15] in performance in career decision-making. Metz and Jones suggested that objective measures of ability assessment only tap into a limited number of abilities (e.g., they do not assess soft skills) and do not address self-perceptions [16]. They argued that self-estimates of ability could fill an open opportunity area in research because most research is based on objective measures of ability assessment. Such assessments are often obtained by asking individuals for their skills directly. However, this type of assessment could be difficult for individuals with limited work experiences or education [16]. Checklists and more formal self-assessment measures can help people identify their skills [16]. Such tools are advantageous because the educational and career options provided help people to expand their career options. However, individuals with limited education and work experience are at a disadvantage.

\subsection{Educational and Employment Disparities}

According to Fouad and Kantamneni, a great deal of research has already identified the significant educational and employment attainment disparities between racial and ethnic minorities ${ }^{1}$ and white European Americans and the causes of these disparities [18]. Educational opportunities equip students with strategies needed to gain employment and support all career competencies. Some secondary and most post-secondary institutions equip students with how to frame their strengths, write resumes and complete application forms; how to interview for jobs and appropriately present themselves at their interviews; and how to perform well at the interview [6]. They also provide students with opportunities to develop their social networks and to learn about and even meet potential employers, which places them at a significant advantage over those who are unable to receive the same level of educational support, namely many racial and ethnic minorities. Thus, racial and ethnic minorities

\footnotetext{
${ }^{1}$ Race refers to a person's biological attributes; ethnicity refers to a person's subjective recognition of cultural and national identity [17].
} 

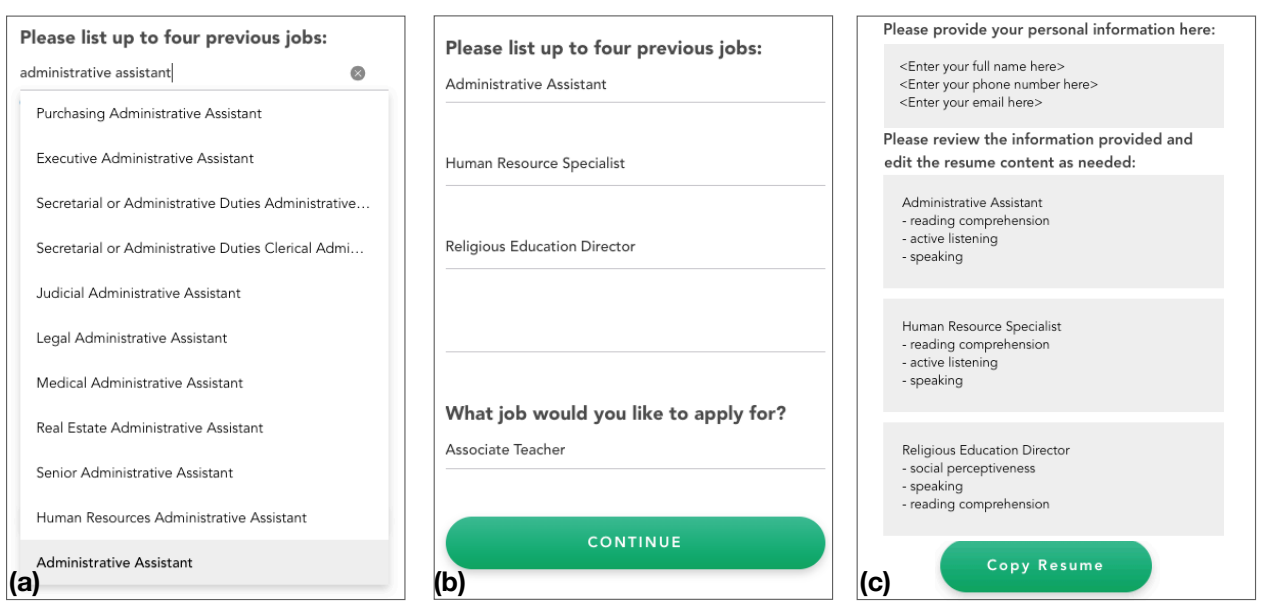

Figure 1. Tool Screenshots. Job seekers: (a) Enter and select job keywords from the drop-down list; (b) Enter up to four previous jobs and one target job; and (c) Tool identifies skills applicable to target job.

often lack access to social networks that are beneficial to employment [19] and role models who are influential in career development [18].

Similar disparities exist online. Technologies that are used for employment are more likely to be used by individuals with a college education or higher and who are relatively affluent [20]. To design more inclusive tools, we must understand how to support people who have traditionally been underrepresented in employment. Skills identification support could lead to improved career identity among these groups, which is an area addressed in this research.

\subsection{Design Guidelines for Employment Tools}

Drawing from vocational, design, and $\mathrm{HCI}$ literature, we discuss design guidelines for employment tools. Savickas et al. posed a series of challenges given the relationships between today's work environment and workers [21]. Their challenges give rise to the need to create and apply new systems of personal promotion and reflection about ways to match one's core self to societal needs. However, the authors made a distinction among employees who they referred to as core, peripheral, or marginalized. Core employees have stable employment and it is recommended that they develop new competencies (by investing in and revamping their current competencies) to make it in a boundaryless labor market. Peripheral workers must learn to cope with numerous transitions throughout their work lives. Marginalized workers are expected to encounter constraints on and additional barriers to their employment - for some, day labor could be their only option. In all cases, regular feedback, self-reflection, and the imagination of possible selves is warranted [21].

Along these lines, past HCI research suggested that marginalized job seekers require feedback, support, trust, and methods to support them in articulating their skill sets and how their skills translate to employment opportunities [7, 22, 23]. HCI scholars have contributed workplace tools to support connections to experts and skill development through mentorship [24] and design recommendations to support low-wage workers' efforts to combat wage theft [25].

More specific to the focus of our work, Dillahunt and $\mathrm{Lu}$ evaluated DreamGigs, a tool to help underrepresented job seekers identify volunteer and employment opportunities that were aligned with their career goals [23]. The authors reported that their participants expressed feelings of empowerment as a result of reflecting on the tool's output as well as by participating in the tool's development. Whereas DreamGigs supports job seekers in identifying a path to reach their ideal or "dream" job, SkillsIdentifier supports job seekers in identifying those skills so they can highlight those skills when applying to a specific job. SkillsIdentifier was the second most preferred conceptualized tool in [7]; the most preferred tool had already been implemented in prior work [22].

SkillsIdentifier identifies how job seekers' current skills overlap with those needed for their targeted job. Job seekers ranked SkillsIdentifier higher than other tools because they saw how the tool could help them identify related skills needed for career transitions and build competitive resumes [7]. We implemented and designed SkillsIdentifier as outlined in this past work.

\section{SkillsIdentifier}

Figure 1 shows tool screenshots; Table 1 illustrates our three-phase iterative design process. We built a proof-of-concept version of the tool, in Phase 1, based on an earlier description of SkillsIdentifier [7]. We iterated over our design and received internal feedback. 


\begin{tabular}{l|l|l|l}
\hline & \multicolumn{1}{|c|}{ PHASE 1 (4 weeks) } & \multicolumn{1}{c|}{ PHASE 2 (4 weeks) } & PHASE 3 (spanned 7 months) \\
\hline $\begin{array}{l}\text { FEEDBACK/ } \\
\text { EVALUATION } \\
\text { SESSION }\end{array}$ & $\begin{array}{l}\text { Internal feedback sessions within } \\
\text { our research group } \\
\text { - Adjusted the number of presented skills } \\
\text { of each past job } \\
\begin{array}{l}\text { Formatted the output skills as a resume } \\
\text { template and allowed users to easily } \\
\text { copy-and-paste }\end{array}\end{array}$ & $\begin{array}{l}\text { Internal feedback sessions within } \\
\text { our research group } \\
\text { - Implemented the tool's back-end using } \\
\text { Firebase }\end{array}$ & $\begin{array}{l}\text { 20 semi-structured interviews with } \\
\text { underrepresented job seekers } \\
\text { - Participants generally liked } \\
\text { Skillsidentifier } \\
\text { Suggested new features } \\
\text { Flexible job titles } \\
\text { - Context-sensitive skill descriptions }\end{array}$ \\
\hline SUMMARY & $\begin{array}{l}\text { Built a Proof-of-concept } \\
\text { Hi-fi Prototype }\end{array}$ & Improved Skillsidentifier's Usability & $\begin{array}{l}\text { Evaluated the Prototype with } \\
\text { Job Seekers }\end{array}$ \\
\hline
\end{tabular}

Table 1. Three-phase design process: Phases 1 and 2: Internal feedback sessions across eight weeks. Phase 3: Evaluation sessions with underrepresented job seekers over a 7-month time window (late 2018 - mid 2019 ).

We incorporated a minimalist design to adhere to prior recommendations. We used the Ionic Framework to build the client side of the tool, which runs in the browser and is agnostic to both operating and hardware systems. This means it could run on an Android or iOS device or a Windows desktop machine, which is particularly important for job seekers who rely on shared devices and who have limited technology access [22]. Our tool did not require authentication, which past work also recommends [22].

SkillsIdentifier relies on the Open Skills API to retrieve jobs and skills data. The Open Skills API was developed by DataAtWork and the University of Chicago [26] to use the Department of Labor's O*NET database [27]. The Open Skills API supports queries for skills, abilities, and knowledge and how they relate to jobs. SkillsIdentifier uses the Open Skills API to auto-complete job titles and retrieve skills associated with the jobs that have been entered. We chose to present up to three skills for each past job entered to keep the resume concise. This enables job seekers to easily copy and paste the content to a resume. Upon reaching a working prototype, we moved to Phase 2 to implement the backend and store user data using Firebase. Finally, we conducted 20 semi-structured interviews with job seekers.

\section{Method}

Our SkillsIdentifier study was part of a 1-month field deployment of two separate employment tools [28], with the entire study spanning 7 months. The other tools focused on other aspects of the job process such as resume building and interview evaluation. At the end of that study, we introduced SkillsIdentifier but kept its evaluation separate from that of the other tools. Although we provided participants with an interview and survey to assess the other tools, we waited until these assessments were done to introduce job seekers to SkillsIdentifier. Thus, the execution of this study occurred separately and the results are treated as such. The length of the full session was between 1 hour and 1.5 hours and the SkillsIdentifier assessment took place in the last half hour. We did not assess SkillsIdentifier longitudinally given the expected one-time use of the tool within a 1-month period. Unlike resume revisions and interview practice sessions over the course of a month, job seekers' past skills were not likely to change significantly within one month. Thus, we separated SkillsIdentifier's evaluation to capture feedback on the tool and asked the same participants to assess the tool at the end of the field deployment.

\subsection{Study Design and Tool Assessment}

First, to help describe the tool, we showed participants storyboards that had been made openly available from the original study [7]. Next, we demonstrated our prototype to participants in situ. Participants then followed instructions to enter their previous jobs and the position they were seeking. We enhanced the originally envisioned version to provide job seekers with their skills displayed as a resume template (see Figure 1c), which listed the skills intersecting between their past and target jobs.

After job seekers went through the skills identified, we interviewed them to gather their overall thoughts about the tool. Sample interview questions included: "What are your thoughts about the skills that were identified based on your past job(s)?" and "How would job seekers like you benefit from a tool like SkillsIdentifier?" We also asked about their past experience articulating skills in their job search. We paid participants \$15 USD for this portion of the study.

\subsection{Recruitment and Participant Overview}

We used offline and online recruiting methods. Participants in the full study [28] were required to have been actively seeking employment for the last 6 months, and have access to either 1) either a digital or physical resume, and 2) an Internet-enabled device. Local workforce development programs aided in our recruitment and agreed to distribute our advertisements. We also used snowball sampling and circulated advertisements in community centers, public libraries, and bus stops located primarily in low-income areas. Finally, we recruited online and used active employment-related Facebook groups (i.e., those with more than 500 members and at least one new post every 


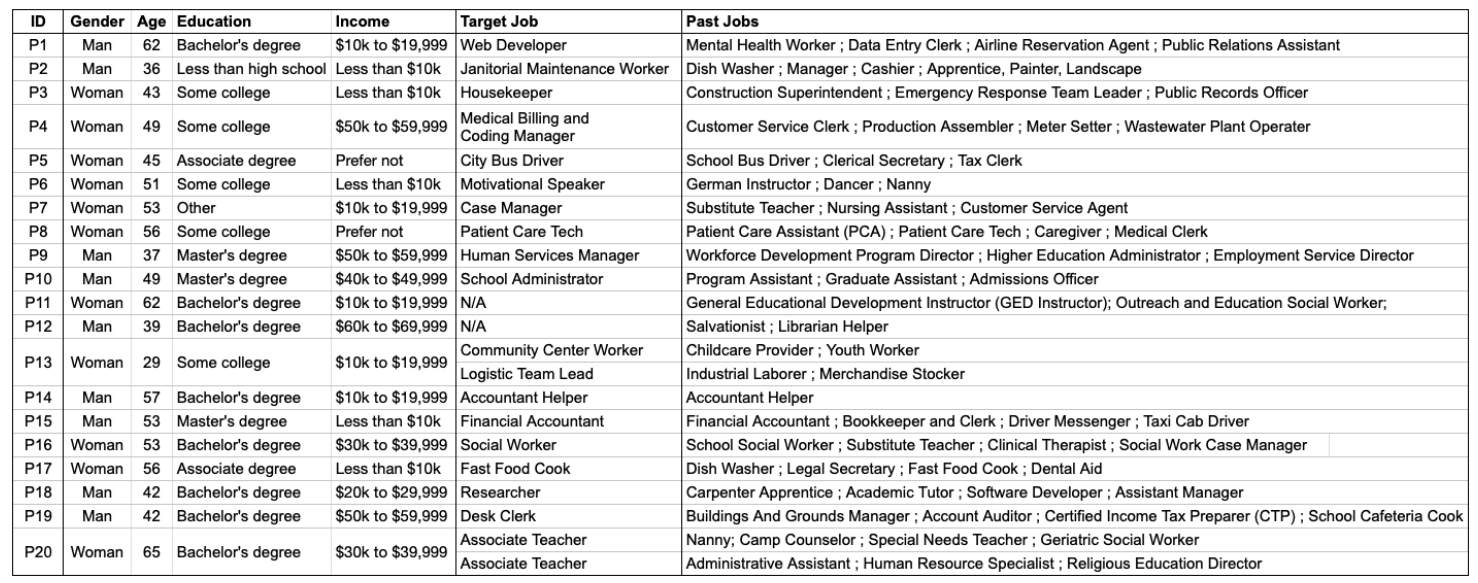

Table 2. Participants: Demographics (Income = annual household income), Target and Past jobs: P13 and P20 attempted two queries. P20 queried the same target job but with two different past job combinations.

day), and Craigslist's volunteer section.

Table 2 includes participants' background information and their targeted and past jobs. We achieved gender balance (women: $\mathrm{N}=11,55 \%$ ). Most participants were middle-aged (Mean=49.0, SD=9.7) and the median annual income for the previous year was $\$ 15,000$. Slightly more than half $(\mathrm{N}=11,55 \%)$ had a bachelor's degree and one participant specified that she earned a nursing certificate, which did not require a bachelor's degree. More than half of our participants were "Black or African American" ( $\mathrm{N}=12,60 \%)$; five were "White" $(25 \%)$; and five specified "Other" $(25 \%){ }^{2}$

\subsection{Data Analysis}

Our dataset included 20 audio recordings of semi-structured interviews, which were professionally transcribed. We also took observation notes that captured users' past and targeted jobs, and we analyzed the transcripts using content analysis. Interview data and participants' information were stored in a secured database. Our analysis aimed to identify 1) how participant's perceived the tool and the tool's benefits, and 2) ways to improve the tool. We adapted initial coding [29] in the first-round analysis by reviewing the transcripts line-by-line. We focused on coding participants' SkillsIdentifier comments (e.g., on the tool's immediate and potential long-term benefits, on the presented skills and tool improvements) and opportunities to develop better employment tools.

In the second-round analysis, we grouped the codes into categories, such as unrealized skills (i.e., skills that were not recognized by job seekers), soft skills (e.g., interpersonal communication skills), and change in self-efficacy (i.e., individuals' internal beliefs about their ability to execute a task [30]). In the

\footnotetext{
${ }^{2}$ Participants had the option to select more than one race in the demographic survey.
}

following rounds of analysis, we iteratively organized the quotes and categories to identify themes related to our research questions. The emerging themes spoke to how participants benefited from SkillsIdentifier and included Raised Skill Awareness, Inspired Reflection and Career Identity, Fostered Self-efficacy, and Fostered Career Exploration. We also had a theme that represented Future Design Opportunities, which included participants' thoughts on how to improve the tool. We address our research questions by presenting each theme as a subsection of our results.

\section{Results}

\subsection{Raised Skill Awareness}

Most participants (N=14, 70\%) found that SkillsIdentifier offered benefits in terms of presenting skills to include on their resumes, cover letters, and interviews. More than half of participants $(\mathrm{N}=13$, $65 \%$ ) had positive feelings about the listed skills and commented that the presented skills were accurate, concise, and detailed. P17 described her thoughts about the presented skills: "I like that it's just precise [sic; concise], it's not wordy." Similarly, P10 stated: "I think all of those [skills] are on point. They're very accurate. Those are definitely the skills you need to possess to be successful in the work that they would require..."

Participants' awareness of their own skills improved. The tool increased their awareness of their transferable skills, or how their skills could be used to complete different jobs. P20 entered administrative assistant, human resource specialist, and religious education director as her past jobs, and she was seeking an associate teacher position (Figure 1c). P20 saw how reading comprehension, a common skill across her past jobs, was relevant to being an associate teacher: "It [SkillsIdentifier] really concretely tells me some of the 
skills that I know I have, but it's nice to know what they are used for in the job market. So that was a good thing that I may not have thought of. Like, reading comprehension, I would not have thought of that. I'm going, 'Oh yeah. You do need that.' When I look at reading comprehension, for example, this, and this, this, [reading comprehension] is in three of them [past jobs] that I just posted... So that was good for me." [P20]

Participants also learned how to articulate their skills. P18, a returning citizen, was inspired to pursue higher education. However, his felony background prevented him from finding intermediate jobs while he prepared graduate school applications. When using the tool, he entered researcher, as his target job, and carpenter apprentice, academic tutor, software developer, and assistant manager as his past jobs. "So if I know that I worked as a carpentry apprentice, I can sort of imagine what I did on the job, but how do I explain that in terms of particular skills? I may not know how to do that, so this [SkillsIdentifier] gives me kind of a hint, a finger pointing in the right direction of how to explain the skills that I may have gained on the job." [P18]

In addition, six participants (P9, P11, P15, P16, P18, \& P20) commented that SkillsIdentifier listed skills that they did not realize they had. P15, who worked previously as a financial accountant, bookkeeper and clerk, courier, and taxi cab driver, entered financial accountant as his target job. He realized, after reading through the skills list, that active listening and speaking were skills that he had but had never considered in the past. "I like [SkillsIdentifier]! ...[T]here are things that I didn't think that I had, and it reminded me. Like active listening. I could listen... I could speak; I'm not afraid of speaking in public...." [P15]

\subsection{Inspired Reflection and Career Identity}

Reviewing their skills helped eight participants reflect on their personal characteristics, or who they are in their job search and career development (P7, P8, P9, P11, P15, P16, P19, \& P20). This strongly resembles career identity and is a reflection of know-why competencies, which answers the question why as it relates to personal meaning, identification, and career motivation. Results suggest that participants experienced know-why competency as it related to personal meaning and identification; however, we did not see support for career motivation.

Job seekers examined these aspects of their identity by entering different combinations of their past jobs and target job. This allowed them to investigate ways to describe themselves and explore new careers. Figure 1a shows an example of SkillsIdentifier's job title suggestions for administrative assistant.

P9's past professional jobs included higher education administrator and employment service director. He was looking for a job as a human services manager $^{3}$ and saw how the overlapping and transferable skills described his personal character and reminded him of who he was: "I think sometimes you end up in the job search and you're pushing so hard that, you know, that kind of helps bring it back to, 'okay what are my skills, what am I good at...' Trying to personalize and tailor things so much towards the job that you're losing some of your actual skill sets. I think this exercise [using SkillsIdentifier] makes me realize that." [P9]

Three participants (P9, P11, \& P15) thought that the listed skills were soft skills and, like P9, agreed that the skills listed were more personal in nature. In this study, we defined soft skills as those skills that are interpersonal (how one handles their interactions with others) and intra-personal (one's ability to manage oneself) in nature [31]. Hard skills are typically skills that are more technical in nature (working with equipment) [31]. Some literature describes hard skills as "learnable" skills and soft skills as more difficult to teach and thus learn. Most of the listed skills were related to interpersonal communication skills or high-level problem-solving skills, such as active listening, public speaking, and reading comprehension. P11, who was planning to develop her own business instead of finding a job after the study, stated: "[A]nd speaking is a skill. I guess I haven't really considered ... because there are a lot of jobs that people don't want to talk to anybody. I guess I really hadn't considered that as skills so maybe this would be eye-opening for me."

\subsection{Fostered Self-efficacy}

Positive change in self-efficacy, individuals' belief in their capacity to perform a specific task [30,32], was also a key finding. Six participants (P6, P8, P13, P15, P16, \& P20) saw that SkillsIdentifier could help them develop confidence in their job search. By showing which skills aligned with their past jobs, they were able to gain a sense of accomplishment (P13) and felt capable (P6). Half of the six (P6, P8, \& P13) participants explicitly stated that they felt more confident after seeing the skills presented. P13, a former childcare provider stated, "[SkillsIdentifier] also helps you to build a sense of accomplishment and be proud of yourself, like 'wow I've managed to master active listening, I've managed to master ... monitoring, somebody trusted me with their children and nothing went wrong,' so it makes you feel

\footnotetext{
${ }^{3}$ Job title returned from Open Skills API, which typically refers to managers in human services agencies.
} 
good." As discussed next, self-efficacy was related to job seekers' career exploration.

\subsection{Fostered Career Exploration}

P5 was an experienced school bus driver looking to drive the city busses. She felt that reviewing skills on SkillsIdentifier could encourage her to explore other job opportunities if she couldn't land her target job. "[Being turned down by employers] can really dampen your spirits so you have to just be adamant and say I'll be there one day. But in the meantime is there another job I can do? That's where [SkillsIdentifier's] ideas come in... Everything that you've already done versus what's available. If none of these are available well what are some things that will always be around - Hospital! Someone will always need to go to the hospital. So that's when you think outside of the box and maybe do something you're not used to if nothing else is available." [P5]

Similarly, P19 had prior experience in multiple accounting-related jobs and SkillsIdentifier inspired him to think about which jobs best represented him: "I was just trying to figure out which [job] from my experience, what I classify to be more fitting for me. So I assume if I were to, say, instead of choosing account auditor, I chose cost accounting, some of those other descriptions would pop up. I will go back and play with [SkillsIdentifier], and do it again."

Two participants (P10 \& P11) saw how the tool could benefit job seekers' career transition. The tool informed job seekers about their transferable skills. P11 stated: "I think [SkillsIdentifier] kind of helps you on your own get focused in to those general things... You might rethink a certain job that you wanted to try for, like, 'Wait a minute. I don't think I have any skills that match.' Maybe you might rethink the job, or identify things you needed to work on ... [like] this job, if you ran it through and you're trying for a new field it may bring up things that you wanted to discuss with the interviewer."

\subsection{Limited in Job Titles and Context}

Despite the aforementioned benefits, we identified two limitations: rigid job titles and vague skill descriptions. SkillsIdentifier relied on the Open Skills API to list jobs and skills. When participants entered their past jobs, they needed to enter job titles that fully matched those stored in the $\mathrm{O} *$ Net database. Three participants (P6, P7, P12) were unable to find their job titles. The job titles were too detailed, according to P14, and it was difficult to choose the best-fit title. P6 received an error after entering German tutor as a past job and found that "German instructor" was accepted.
"[W]hen I put in German tutor, then I was irritated by the fact that [SkillsIdentifier] said it wasn't accurate. You might put a sentence at the top that says, 'Choose from the pop-up list,' right?" [P6]

Eight participants (P1, P4, P7, P10, P11, P14, P15, \& P18) identified a second limitation-the listed skills were too general. Four participants (P1, P4, P14, \& P18) believed this to be caused by the lack of context provided. Participants pointed out that a skill might have different meanings in different job contexts. P1 discussed how active listening held different meanings across his three past jobs as a public relations assistant, an airline reservation agent, and mental health partner: "Once you get the position [public relations assistant], then you become more active listening to the client's description of what is necessary to do to promote their business ... Also, with the airline reservation agent, you develop as they talk, what you think they're getting at with their needs... You really have to look into all the different aspects of listening ... When I was a mental health partner, you're listening [sic] was clues to a lot of things. The clues to, is this client, patient depressed? Is they [sic] going through some sort of mental episode?"

Finally, P15 thought that the soft skills identified could not be used. Although soft skills were good for job seekers to review, they might not be practical to include in job search materials: "You cannot put on [a] resume, 'I have active listening,' or something. You know what I mean? It is hard to present it to somebody.” [P15]

\section{Discussion}

We implemented and evaluated SkillsIdentifier among 20 Midwestern U.S. job seekers who consisted primarily of racial minorities, women, and lower-income individuals, reflecting those of the highest unemployed groups in the country. Forty-five percent of our job seekers held less than a college degree. Our study results answer the research question: "How does SkillsIdentifier influence underrepresented job seekers on skill articulation? And why or why not?" In summary, SkillsIdentifier has the potential to support job seekers managing career transitions, which is aligned with prior research [7]. The majority of our participants liked SkillsIdentifier and saw its benefits (e.g., preparing resumes, cover letters, and interviews). The tool helped job seekers find words to describe their skills and raise awareness of their career identity, which fostered self-efficacy. However, in a few cases, participants were unable to describe their soft skills.

After identifying how SkillsIdentifier influenced underrepresented job seekers and the factors that led to these effects, we contribute the following 
four design recommendations for employment tools to support this population: 1) improve know-why career competencies; 2) improve know-how career competencies by framing soft skills; 3) foster self-efficacy; and 4) encourage reflection and career exploration. Half of our recommendations relate to improving career competencies. These consist of: career reflection, which is concrete thinking about one's own motivation and aptitude; career exploration, which helps to shape one's own career path by exploring study and work options; career action, which is steering one's own learning process; and networking to build and maintain a social network [11]. Education access enables students to think about such topics and connect to supporting resources. People are less likely to have this opportunity, however, without access to educational resources. Therefore, it is vital for future employment tool design to support underrepresented job seekers. SkillsIdentifier complements and extends past work that aimed to provide job seekers with pathways to acquire the skills needed to achieve their "dream job" [23]. SkillsIdentifier displays skills to convey on a resume or articulate in an interview and enables job seekers were able to reflect and improve their self-efficacy based on these skills. We discuss our results in the context of the career competencies literature.

Improving know-why competencies: SkillsIdentifier helped to activate know-why and know-how competencies, which correspond directly to career reflection and career action. Recall that know-why competencies answer the question why as it relates to personal meaning, identification, and career motivation. Although we did not see evidence of career motivation, SkillsIdentifier appeared to assist job seekers in clarifying their personal meaning and identification. As suggested in past research [21], self-reflection and the imagination of possible selves are needed to support career identity and to overcome the constraints that marginalized, core, and peripheral, workers encounter. Employment tool designers aiming to support underrepresented job seekers should improve career competencies by encouraging the imagination of possible selves and further investigate the relationship between career motivation and personal meaning.

Improving know-how competencies-framing soft skills: Although some job seekers had mixed feelings about the importance of soft skills, job seekers' awareness of their skills and career identities improved, which aligns with past work [33]. Hard skills awareness was effective for job seekers but did not allow them to explore-these skills in some ways could limit job seekers by boxing them into specific opportunities. Our results suggest that SkillsIdentifier had the potential to increase job seekers' self-efficacy and inspire them to think through know-why competencies as a by-product of becoming more aware of their skills.

Know-how competencies are reflected in job-related skills and abilities through training or other development activities. This tension is interesting because these skills are particularly important given that $21^{\text {st }}$-century skills required for today's dynamic work environment (e.g., critical thinking and problem solving) are emphasized more than they have been in the past [34]. Participants' reflections on their soft skills were crucial to their ability to reflect on their identity, or know-why competencies. These competencies help to answer the question why as it relates to personal meaning, identification, and career motivation and shape people's abilities to make sense of their evolving work agendas. Further, as motivated in our related work, tools that support job seekers' know-how competencies are extremely valuable in the context of today's work environment [13].

SkillsIdentifier assisted job seekers in gaining self-knowledge. Self-knowledge is necessary to reach career identity, which has been associated with varying career-related and well-being outcomes [35]; less career self-doubt [36]; and improved reasoning about future career opportunities [37]. Interventions that aid job seekers in self-knowledge also provide context to job seekers about where they can be satisfactory workers, which helps to enhance work adjustment and ease occupational choice making [8]. Outcomes of this type of guidance are immediate and include enhanced self-confidence and self-esteem, which increases one's motivation to consider new employment options [38].

Foster self-efficacy: Similarly, our results suggest that job seekers' reflection on who they wish to be increased their self-efficacy and, as prior research suggested, led to less self-doubt [36]. Self-efficacy, defined as individuals' confidence in their ability to successfully engage in a specific behavior [30, 32], has been applied successfully to career development [6]. Self-efficacy can help in terms of coping with unemployment and lead to favorable employment outcomes. Self-efficacy-promoting interventions are associated with job seekers' commitment in the job search process. Building on this past research, interventions that allow job seekers to reflect on parts of the job process starting from the skills they have, as seen in our current study, to their performance in interviews, could improve self-efficacy. HCI research suggests that providing positive feedback and features that enable job seekers to reflect on how their interview performance could lead to positive self-efficacy [28]. Finally, it's important to keep in mind the broader guidance and counselling research that finds self-efficacy to 
be especially pertinent to the needs of disempowered societal groups [39]. These findings are critical in a time of evolving boundaryless careers. Self-efficacy appears to foster career exploration, and we should continue exploring ways for tools to improve self-efficacy in the future.

Encouraging reflection and career exploration: We should also consider designs that enable job seekers to reflect based on their identified skills. This helps to increase their self-knowledge and consideration for their career identity, and it supports job seekers in fully exploring their career identities. Although existing HCI tools have supported job seekers in understanding career pathways [23], very few emphasize the career and career identity exploration or encourage reflection [40]. This is especially important for job seekers who might lack a traditional education or have limited access to mentors. Prior HCI work suggested that reflection on the number of jobs applied to might also be beneficial [5]; however, it is unclear whether such reflection fosters self-efficacy.

Job seekers felt more accomplished and capable as a result of reflecting on their skills, which led to further exploration. This type of exploration and exposure to careers is needed for job seekers to fully explore new opportunities. We must also keep in mind that slightly more than half of our participants reported their race as Black or African American and their gender as women. It is important to consider that these minority group members are limited to certain careers because of their ethnicity and gender [41, 42], and they experience bias in online career searches [43]. Therefore suggesting career opportunities outside their targeted jobs and that they have the skills to fulfill might be beneficial. Such engagement strategies are one of the most important challenges facing the career counseling profession [44, 45]. Figure 1a demonstrates how SkillsIdentifier exposed a job seeker targeting a position as an administrative assistant to different roles (e.g., executive and purchasing administrative assistants). Although some participants did not appreciate the rigidity of job titles, as described in subsection 5.5, showing related positions could encourage exploration and exposure. Future designs should simplify finding specific job titles while also increasing job seekers' exposure to new opportunities.

Limitations: We acknowledge three study limitations. First, job seekers assessed SkillsIdentifier at a single point in time, which prevents us from understanding long-term effects. This is a shortcoming found in many employment-related studies [6]. Second, this study was limited to a single U.S. region and employment varies across geographic, political, and cultural contexts [6]. Our small sample, which is on par with qualitative HCI research, was another limitation.

\section{Conclusion and Future Work}

We developed and evaluated SkillsIdentifier, a tool to assist job seekers in identifying their current skill sets to strengthen their resumes before applying to jobs. The results of our evaluation of 20 U.S. underrepresented job seekers suggest that helping job seekers identify and articulate their skill set could foster their career identity and self-efficacy. Broadly, this supports underrepresented job seekers' ability to transition to new jobs within a boundaryless career environment.

Our work is a first step to integrating job seeker feedback into future design iterations before longitudinal assessment. Future research should investigate the extent to which our results generalize outside the U.S. and to other populations facing employment disparities such as women, neurodiverse groups, and people with different levels of digital literacy. Future researchers should also consider ways to overcome recruitment challenges $[28,46]$.

\section{Acknowledgments}

This research was supported by the NSF award IIS-1717186. We thank our participants, our community partners, and our colleagues who provided feedback.

\section{References}

[1] Y. Guan, M. B. Arthur, S. N. Khapova, R. J. Hall, and R. G. Lord, "Career boundarylessness and career success: A review, integration and guide to future research," J of Vocat Behavior, vol. 110, 2019.

[2] R. J. DeFillippi and M. B. Arthur, "The boundaryless career: A competency-based perspective," J of Org Behav, vol. 15, no. 4, 1994.

[3] T. R. Dillahunt and A. R. Malone, "The promise of the sharing economy among disadvantaged communities," CHI '15, 2015.

[4] D. G. Hendry, J. P. Woelfer, and T. Duong, "U-district job co-op: constructing a future vision for homeless young people and employment," Information Technology \& People, vol. 30, 2017.

[5] E. Wheeler and T. R. Dillahunt, "Navigating the job search as a low-resourced job seeker,' CHI '18, 2018.

[6] C. R. Wanberg, A. A. Ali, and B. Csillag, "Job seeking: The process and experience of looking for a job," Annual Rev of Org Psych and Org Behav, vol. 7, no. 1, 2020.

[7] T. R. Dillahunt, J. Lam, A. Lu, and E. Wheeler, "Designing future employment applications for underserved job seekers: A speed dating study," DIS '18, 2018.

[8] M. L. Savickas, "Career construction: A developmental theory of vocational behaviour," in Career Choice and Devt (D. Brown, ed.), ch. 5, 4 ed., 2002. 
[9] V. Wilson, "2019 Q3-Q4: State unemployment by race and ethnicity (Economic Policy Institute)."

[10] A. Praskova, P. A. Creed, and M. Hood, "Career identity and the complex mediating relationships between career preparatory actions and career progress markers," $J$ of Vocat Behavior, vol. 87, 2015.

[11] M. Kuijpers and J. Scheerens, "Career competencies for the modern career," J of Career Devt, vol. 32, no. 4, 2006.

[12] L. T. Eby, M. Butts, and A. Lockwood, "Predictors of success in the era of the boundaryless career," J of Org Behav, vol. 24, no. 6, 2003.

[13] A. Forrier and L. Sels, "The concept employability: A complex mosaic," Int J of Human Resources Devt and Management, vol. 3, no. 2, 2003.

[14] R. W. Lent, S. D. Brown, and G. Hackett, "Toward a unifying social cognitive theory of career and academic interest, choice, and performance," $J$ of Vocat behavior, vol. 45, no. 1, 1994.

[15] D. E. Super, M. L. Savickas, and C. M. Super, "The life span, life space approach to careers," in Career Choice and Devt: Applying Contemporary Theories to Practice (D. Brown and L. Brooks, eds.), 1996.

[16] A. J. Metz and J. Jones, "Ability and aptitude assessment in career counseling," in Career devt and counseling: Putting theory and research to work (S. D. Brown and R. W. Lent, eds.), ch. 16, 2 ed., 2013.

[17] T. A. Sheldon and H. Parker, "Race and ethnicity in health research," J of Public Health, vol. 14, 061992.

[18] N. A. Fouad and N. Kantamneni, "The role of race and ethnicity in career choice, development, and adjustment," in Career Devt. and Counseling: Putting Theory and Research to Work (S. D. Brown and R. W. Lent, eds.), ch. 8, Wiley NWC City, NY, 2 ed., 2013.

[19] K. S. Seefeldt, Abandoned Families: Social Isolation in the 21st Century. Russell Sage Foundation, 2017.

[20] B. Jen, J. Kaur, J. De Heus, and T. R. Dillahunt, "Analyzing employment technologies for economically distressed individuals," CHI EA '14, 2014.

[21] M. L. Savickas, L. Nota, J. Rossier, J.-P. Dauwalder, M. E. Duarte, J. Guichard, S. Soresi, R. van Esbroeck, and A. E. van Vianen, "Life designing: A paradigm for career construction in the 21st century," J of Vocational Behav, vol. 75, no. 3, 2009.

[22] T. R. Dillahunt, N. Bose, S. Diwan, and A. Chen-Phang, "Designing for disadvantaged job seekers: Insights from early investigations," DIS '16, 2016.

[23] T. R. Dillahunt and A. Lu, "DreamGigs: Designing a Tool to Empower Low-Resource Job Seekers," CHI '19, 2019.

[24] J. S. Hui, D. Gergle, and E. M. Gerber, "Introassist: A tool to support writing introductory help requests," CHI '18, 2018.

[25] L. Dombrowski, A. Alvarado Garcia, and J. Despard, "Low-wage precarious workers' sociotechnical practices working towards addressing wage theft," CHI '17, 2017.

[26] Data At Work, "Open skills api." http://dataatwork.org/data/, n.d.

[27] The Department of Labor, "O*net online." https:// www. onetonline.org/, n.d.

[28] T. R. Dillahunt and J. C.-Y. Hsiao, "Positive feedback and self-reflection: Features to support self-efficacy among underrepresented job seekers,' CHI '20, 2020.
[29] J. Saldaña, The Coding Manual for Qualitative Researchers. SAGE Publications Ltd, 3 ed., 2015.

[30] A. Bandura and D. Cervone, "Self-evaluative and self-efficacy mechanisms governing the motivational effects of goal systems," J of Personality and Social Psychology, vol. 45, no. 5, 1983.

[31] D. R. Laker and J. L. Powell, "The differences between hard and soft skills and their relative impact on training transfer," Human Resource Devt Q, vol. 22, no. 1, 2011.

[32] A. Bandura, "Self-efficacy," in The Corsini Encyclopedia of Psychology, pp. 1-3, American Cancer Society, 2010.

[33] F. Meijers, M. Kuijpers, and C. Gundy, "The relationship between career competencies, career identity, motivation and quality of choice," Int J for Educ and Vocat Guidance, vol. 13, no. 1, 2013.

[34] A. J. Rotherham and D. T. Willingham, "21st-century skills," Am Educator, vol. 17, no. 1, pp. 17-20, 2010.

[35] V. B. Skorikov and F. W. Vondracek, "Occupational identity," in Handbook of identity theory and research, Springer, 2011.

[36] E. J. Porfeli, B. Lee, F. W. Vondracek, and I. K. Weigold, "A multi-dimensional measure of vocational identity status," J of Adolesc, vol. 34, no. 5, 2011.

[37] P. A. Klaczynski and K. L. Lavallee, "Domain-specific identity, epistemic regulation, and intellectual ability as predictors of belief-biased reasoning: A dual-process perspective," J of Experimental Child Psychology, vol. 92, no. 1, 2005.

[38] D. Hughes, S. Bosley, L. Bowes, and S. Bysshe, "The economic benefits of guidance," tech. rep., 2002.

[39] P. J. Robertson, "Developing career capabilities in "neet" young people: experiences of participants in the prince's trust team programme," British J of Guidance \& Counselling, vol. 46, no. 6, 2018.

[40] T. R. Dillahunt, S. Ng, M. Fiesta, and Z. Wang, "Do massive open online course platforms support employability?," CSCW '16, 2016.

[41] V. J. Carroll McCollum, "Career development issues and strategies for counseling african americans," J of Career Devt, vol. 25, no. 1, 1998.

[42] D. A. Luzzo and E. H. McWhirter, "Sex and ethnic differences in the perception of educational and career-related barriers and levels of coping efficacy," J of Counseling \& Devt, vol. 79, no. 1, 2001.

[43] M. Kay, C. Matuszek, and S. A. Munson, "Unequal representation and gender stereotypes in image search results for occupations," CHI '15, 2015.

[44] K. B. Hoyt, "The career status of women and minority persons: A 20-year retrospective," The Career Devt $Q$, vol. 37 , no. 3, 1989.

[45] F. T. L. Leong, ed., Career developmentt and vocational behavior of racial and ethnic minorities. 1995.

[46] X. Xu, X. Yan, and T. R. Dillahunt, "Reaching hard-to-reach populations: An analysis of survey recruitment methods," in Conf. Comp. Pub. of CSCW '19, 2019. 